\title{
Unveiling electrostatic portraits of quinones in reduction and protonation states
}

\author{
SUBHASH S PINGALE ${ }^{\mathrm{a}, *}$, ANUJA P WARE ${ }^{\mathrm{a}}$ and SHRIDHAR R GADRE \\ ${ }^{a}$ Department of Chemistry, Savitribai Phule Pune University, Pune, Maharashtra 411 007, India \\ b Interdisciplinary School of Scientific Computing, Savitribai Phule Pune University, Pune, \\ Maharashtra 411 007, India \\ E-mail: sspingale@chem.unipune.ac.in
}

MS received 28 November 2017; revised 8 March 2018; accepted 20 March 2018; published online 26 April 2018

\begin{abstract}
Quinones are known to perform diverse functions in a variety of biological and chemical processes as well as molecular electronics owing to their redox and protonation properties. Electrostatics chiefly governs intermolecular interaction behaviour of quinone states in such processes. The electronic distribution of a prototypical quinone, viz., $p$-benzoquinone, with its reduction and protonation states (BQS) is explored by molecular electrostatic potential (MESP) mapping using density functional theory. The reorganization of electronic distribution of BQS and their interaction with electrophiles are assessed for understanding the movement of ubiquinone in bacterial photosynthetic reaction centre, by calculating their binding energy with a model electrophile viz., lithium cation $\left(\mathrm{Li}^{+}\right)$at B3LYP/6-311+G(d,p) level of theory. The changes in the values of the MESP minima of BQS states alter their interacting behaviour towards $\mathrm{Li}^{+}$. A good correlation is found between the value of MESP minimum of BQS and the $\mathrm{Li}^{+}$binding strength at the respective site. To acquire more realistic picture of the proton transfer process to quinone with respect to its reduction state in the photosynthetic reaction center, interaction of BQS with model protonated motifs of serine, histidine as well as $\mathrm{NH}_{4}^{+}$is explored. Further, the electronic conjugation of the reduced states of 9,10 -anthraquinone is probed through MESP for understanding the switching nature of their electronic conductivity.
\end{abstract}

Keywords. Quinones; redox; molecular electrostatic potential; molecular conjugation; cation binding.

\section{Introduction}

Quinones are a widely recognized class of organic compounds, ubiquitously found in the nature, with wide applications in a variety of disciplines such as electrochemistry, biology, medicinal chemistry, synthetic chemistry and nanotechnology. The quinonehydroquinone redox couple serves as a prototypical example of the organic redox electrode used in $\mathrm{pH}$ measurements as it shows the change in potentiometric or polarographic potential with the change in $\mathrm{pH} .{ }^{1,2}$ The reduction of quinone to hydroquinone is a singlestep two-proton two-electron reaction in the acidic $\mathrm{pH}$ and only a two-electron one in the alkaline medium. ${ }^{1}$ However, it is either two-electron one-proton or only two-electron reaction ${ }^{1}$ in the neutral $\mathrm{pH}$.

\footnotetext{
*For correspondence
}

The applicability of quinones in various fields, mainly in biological energy transduction processes such as photosynthesis and respiration, is a consequence of their ability to undergo sequentially reversible proton and electron transfer reactions for the interconversion of quinones to the respective quinol forms. ${ }^{3}$ Ubiquinones are found in the mitochondrial respiratory chain complexes viz., Complex I (NADH:ubiquinone oxidoreductase), Complex II (succinate:quinone oxidoreductase) and Complex III (ubiquinol:cytochrome c oxidoreductase), wherein electron transfer from $\mathrm{NADH}$ to $\mathrm{O}_{2}$ is executed by quinone-to-quinol redox reactions. ${ }^{4}$ In symmetric photosynthetic type II reaction center, viz., PSII, of plant and bacterial reaction centers (RCs), photoexcited electrons are transferred through various acceptors of the side $A$ to quinone $Q_{A}$ (ubiquinone or plastoquinone) and then to quinone $\mathrm{Q}_{\mathrm{B}}$, at the side $\mathrm{B} .{ }^{5-7}$ Further, by accepting two electrons and two protons, $\mathrm{Q}_{\mathrm{B}}$ transforms into quinol $\mathrm{Q}_{\mathrm{B}} \mathrm{H}_{2}$ via various reduction 
and protonation states. Then $\mathrm{Q}_{\mathrm{B}} \mathrm{H}_{2}$ passes into the membrane, guided by the weak intermolecular interactions such as hydrogen bonding (H-bonding), and releases electrons and protons to get re-oxidized. This transfer of protons generates a proton gradient around the cell membrane which is responsible for the ATP synthesis. ${ }^{7}$ Extensive experimental and theoretical research has been done for understanding the mechanism of the key steps in the photosynthetic process, viz., binding of $Q_{B}$ in the protein pockets and its transformation to $\mathrm{Q}_{\mathrm{B}} \mathrm{H}_{2}$. Various X-ray crystallographic and site-directed mutagenesis studies suggest that structural and functional features of amino acid residues are involved in the binding ${ }^{8}$ and migration of $\mathrm{Q}_{\mathrm{B}} \cdot{ }^{6,9}$ Stowell et al., ${ }^{10}$ analysed the crystal structures of bacterial photosynthetic $\mathrm{RC}$ of Rhodobacter sphaeroid under light illumination and in the dark. They observed that in the dark-adapted structure, ubiquinone $\mathrm{Q}_{\mathrm{B}}$ is situated at distal site (away from non-haem iron) with the particular framework of $\mathrm{H}$-bonds formed between its carbonyl oxygens and surrounding amino acid viz., His-L190. However, in the light-adapted structure, with electron transfer, the $\mathrm{Q}_{\mathrm{B}}$ have been found to have undergone a displacement of $\sim 4.5 \AA$ towards proximal site (closest to non-haem iron) with $180^{\circ}$ propeller twist showing H-bonding interaction with His-L190 and Ser-L223 from where it receives the protons through various pathways. ${ }^{10,11}$ Such type of migration of $Q_{B}$ was also observed by Lancaster and Michel ${ }^{12}$ in the RC of another bacterial species Rhodopseudomonas viridis. They noticed hydrogen bonding interaction of $\mathrm{Q}_{\mathrm{B}}$ with similar bonding interaction as observed by Stowell et al., ${ }^{10}$ at proximal site. Further, it was suggested ${ }^{6,13}$ that the $\mathrm{Q}_{\mathrm{B}}$ is observed in different redox states viz., neutral, semiquinone anion $\left(\mathrm{Q}_{\mathrm{B}}^{-}\right.$and $\left.\mathrm{Q}_{\mathrm{B}} \mathrm{H}^{-}\right)$and as fully protonated dihydroquinone $\left(\mathrm{QH}_{2}\right)$ in crystal structures of RCs. According to the crystal structure reported by Stowell et al., ${ }^{10}$ anionic $\mathrm{QB}^{\bullet-}$ exists in the proximal site. On the other hand, the neutral quinone state was reported to be at the proximal site in the X-ray crystal structure given by Lancaster et al. ${ }^{12}$ Breton et al., ${ }^{14}$ performed FTIR vibrational spectroscopic study to gain insights of distinct $\mathrm{Q}_{\mathrm{B}}$ interactions at the two different binding sites in Pro-L209 $\rightarrow$ Tyr mutant RC and concluded that the proximal binding site is dominant for neutral $\mathrm{Q}_{\mathrm{B}}$. With the mutagenesis and kinetic investigation of electron transfer in the RC of Rhodobacter sphaeroid, Takahashi et al., ${ }^{15}$ suggested that electrostatics plays a crucial role in the interaction of quinone states with the surrounding amino acids. Special attention has also been drawn to the importance of binding affinities of the different states of ubiquinone for performing their functions in the RC. Manojkumar et al., ${ }^{16}$ have studied the structural, electronic and spectral properties of $\mathrm{H}$ - bonded complexes of $\mathrm{BQ}$ and its anionic forms, viz., $\mathrm{BQ}^{\bullet-}$ and $\mathrm{BQ}^{2-}$ with one- and two water molecules for examining the effect of $\mathrm{H}$-bonding on the complexes in different electronic states of BQ using varied levels of theoretical methods. They observed that the interaction energies of $\mathrm{BQ}^{\bullet-}$ and $\mathrm{BQ}^{2-}$-water monomer/dimer complexes are more favourable than the respective neutral BQ complexes by $\sim 2.6$ and $\sim 6.0 \mathrm{kcal} \mathrm{mol}^{-1}$ due to the increase in $\mathrm{H}$-bond strength (by $\sim 2 \mathrm{kcal} \mathrm{mol}^{-1}$ ) in the reduced species. Nepal et al., ${ }^{17}$ recently studied, using the DFT method, the $\mathrm{H}$-bonding interactions of $o$ quinone and its radical semiquinone anion with several proton donor molecules viz., dimethylamine, methanol, ethanol, dimethylurea and a strong cationic species, viz., $\mathrm{CNH}_{2}\left(\mathrm{NHCH}_{3}\right)_{2}^{+}$. They visualized the MESP regions and qualitatively assessed the $\mathrm{H}$-bonding ability of $o$ quinone substituted with the electron-donating $\mathrm{NH}_{2}$ and electron-withdrawing $\mathrm{Cl}$ groups. The study revealed that the cationic proton donor species $\mathrm{CNH}_{2}\left(\mathrm{NHCH}_{3}\right)_{2}^{+}$ forms more stabilized multi $\mathrm{H}$-bonded complexes with $o$-quinone and its radical semiquinone anion than with the other species. In particular, they observed a remarkable increase in binding energies for the complexes of cationic H-bonded donor $\mathrm{CNH}_{2}\left(\mathrm{NHCH}_{3}\right)_{2}^{+}$with $o$ semiquinone radical anion than complexes with neutral $o$-quinone by a factor of 4.3 .

Quinones also have potential applications in the emerging field of molecular electronics devices such as single molecular switches. ${ }^{18-20}$ Molecular switch is a device that alters the conductance on or off by changing its molecular states in response to external stimuli such as electric field, temperature, light, etc. ${ }^{21}$ Markussen et al. ${ }^{22}$ analysed theoretically the switching mechanism in anthraquinone (AQ)/hydroanthraquinone $\left(\mathrm{AQH}_{2}\right)$ redox couple. They calculated molecular electronic conductance of a molecule containing central 9,10 -anthraquinone $\pi$-conjugated with ethyne as a main spacer unit and phenylsulfanyl at both the ends as a linker group to the electrode using ab-initio non-equilibrium Green-functions (DFT-GF) method. Smaller electronic conductance observed in AQ than in $\mathrm{AQH}_{2}$ has been attributed to presence of destructive interference in the former one. In line with this, Seidel et al., ${ }^{23}$ synthesized and characterized the 9,10anthraquinone spacer unit as used by Markussen et al., ${ }^{22}$ but using thienyl linkers to investigate their application as redox-active switches. Cyclic voltammetry measurements performed by Seidel et al. ${ }^{23}$ showed the occurrence of two fully reversible reduction waves confirming that the compound can be switched electrochemically between $\mathrm{AQ}$ and $\mathrm{AQH}_{2}$ states. They also calculated the electron transport characteristics of $\mathrm{AQ}$ and $\mathrm{AQH}_{2}$ forms of spacer unit using DFT-GF 
approach and observed $\sim 4$ times higher conductance for $\mathrm{AQH}_{2}$ than $\mathrm{AQ}$. Furthermore, Darwish et al., ${ }^{18}$ developed $\mathrm{AQ} / \mathrm{AQH}_{2}$ redox couple-based norbornylogous bridge tetrathiol single molecular switch and showed experimentally that the low conducting AQ moiety can be switched electrochemically and reversibly to high conducting $\mathrm{AQH}_{2}$ one using scanning tunnelling microscopy (STM) break junction technique. A redox-mediated on/off fluorescence-based switching mechanism has recently been observed by Greene et al., ${ }^{24}$ with 2,3-dimethoxy-1,4-benzoquinone linked to boron-dipyrromethene fluorophore segment. For this molecule, the intramolecular photoinduced electron transfer (PeT) has been observed with quenching in its fluorescence activity when quinone is present in its oxidized form. However, the reduction of quinone to quinol form deactivates the intramolecular PeT and the molecule shows fluorescence emission. With these findings, Greene et al. ${ }^{24}$ anticipated that this redox mediated reversible quinone/quinol off/on couple can be applied to understand and monitor complex redox processes without disturbing the system and to develop probes which sensitively monitor electron transfer in biological cellular respiration systems such as mitochondria.

In summary, it seems that the mechanism of binding, migration of secondary electron acceptor $\mathrm{Q}_{\mathrm{B}}$ (in its various redox states) and further reduction to quinol in the protein binding pockets is yet not completely clear. ${ }^{13}$ Furthermore, it seems that quinone in its reduced states conduct electronic charge differently, which makes quinone as a potential candidate for molecular electronic switch. Can one explain the mechanism in a simple way using the concept of electronic conjugation?

For the characteristic functioning of quinone (Q) in the above mentioned areas of research, Q should be present in its specific state. Quinone is capable of adopting different reduction and protonation states $(c f$. Figure 1). ${ }^{25}$ Of these states, $\mathrm{QH}^{+}, \mathrm{QH}_{2}^{2+}$ and $\mathrm{QH}_{2}^{\bullet+}$ are generated only under extreme conditions. However, the other intermediate states viz., quinone radical anion $\left(\mathrm{Q}^{\bullet-}\right)$, semiquinone radical $\left(\mathrm{QH}^{\bullet}\right)$, semiquinone anion $\left(\mathrm{QH}^{-}\right)$and hydroquinone $\left(\mathrm{QH}_{2}\right)$ states manifest their characteristic roles in quinone electrochemistry and biological processes. ${ }^{25}$

Reduction or protonation reactions interconvert ${ }^{2}$ one quinone state to other ( $c f$. Figure 1). Such conversions alter the non-covalent (such as H-bonding and cation binding) intermolecular interaction behaviour, which controls the functions of quinones in the respective redox biological centres and molecular electronic switches. ${ }^{26-28}$ Much of the previous work has focused on the comparison of geometries, vibrational spectra and spin properties of the reduction and protonation

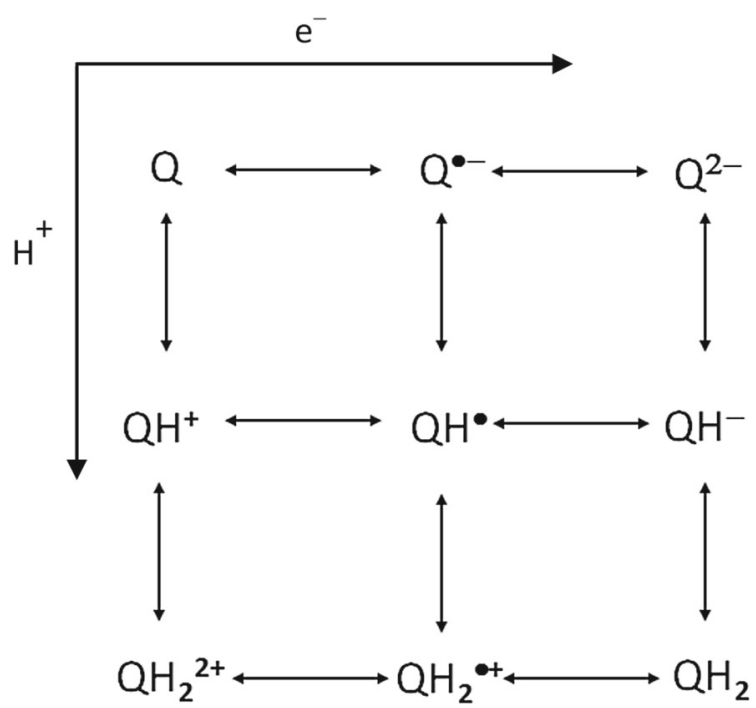

Figure 1. Possible reduction and protonation states of quinone $(\mathrm{Q})$. See text and Reference 34 for details.

states of $p$-benzoquinone (BQS), a prototype of class of quinones. ${ }^{2,16,29-31}$ These BQS states (depicted in Figure 1) were employed by Nonella ${ }^{25}$ and Zhao et al., ${ }^{32}$ for providing basic data for the analysis of the vibrational spectra of biological quinones. Manojkumar et al., ${ }^{16}$ studied the structures, energetics and spectra of hydrated BQ and the corresponding anions for examining the effect of $\mathrm{H}$-bonding on these properties of the BQS.

Electrostatics is known to play a key role in the noncovalent interactions. ${ }^{11,33-43}$ In view of this, obtaining a complete picture of the electrostatic nature of all the possible reduction and protonation states of quinone and correlating its effect on their cation-binding behaviour seems worthwhile. Especially, the understanding of noncovalent interactions involving metal ion binding is expected to provide valuable insights for structural and functional properties of molecular systems. ${ }^{44}$ Particularly, the site of metal cation binding confirms the electron localization in the corresponding region of a molecular system. ${ }^{40}$

Molecular electrostatic potential (MESP) is a scalar field, used extensively ${ }^{38,45-47}$ in the literature for exploring reactivity patterns of molecules and their noncovalent interactions. Particularly, it is a well-recognized property for investigating the sites for electrophilic attack. ${ }^{33-43}$ Gadre et al.,${ }^{41}$ studied the H-bonded complexes of HF with some molecules and established the relationship between the H-bond length and position of the most negative MESP minimum of $\mathrm{H}$-bonded complexes with a remarkable correlation coefficient of 0.96 . They also developed ${ }^{37,38 b, c}$ a model showing a good correlation between MESP topographical features 
and binding patterns in weakly bonded complexes. Furthermore, Pingale ${ }^{48}$ successfully employed the MESP topography as a quantitative measure of strength of electronic conjugation of some organic $\pi$-conjugated systems such as dimers of ethylene, benzene, furan, etc., by means of MESP values of conjugation critical points (CCPs), which connect the two molecular electron localized regions. Deep negative MESP value at the $\mathrm{CCP}\left(\mathrm{V}_{\mathrm{CCP}}\right)$ indicates a large extent of conjugation in the respective molecular electronic regions. ${ }^{48}$

Though the quinone moieties in various reduction and protonation states play crucial role in the processes of various disciplines, ${ }^{3,7,18}$ we focus on photosynthesis and molecular switches in the present study. For both the processes, i.e. movement of $\mathrm{Q}_{\mathrm{B}}$ moiety and its protonation based on electrostatic interactions of specific reduction or protonation states of quinone with surrounding amino acids in $\mathrm{RC}$ and varied amount of electron/charge transfer through $\mathrm{Q}$ to $\mathrm{QH}_{2}$ states, the electronic distribution of each quinone state is key parameter for understanding their mechanisms. In the present work, three-dimensional mapping of MESP of the quinone states is employed with a view to understand the mechanism of the above processes.

\section{Computational details}

The geometries of $\mathrm{BQS}$ and $\mathrm{BQS} \cdots \mathrm{Li}^{+}$systems are optimized at the B3LYP/6-311+G(d,p) (for closed shell states) and UB3LYP/6-311+G(d,p) (for open shell states) levels of theory in gas phase using GAUSSIAN09 package. ${ }^{49}$

The electrostatic nature and regions of electron localization of BQS are explored by MESP analysis. The MESP, V(r), a measure of an interaction with a unit positive charge, at a point $\mathbf{r}$ is defined as:

$\mathrm{V}(\mathbf{r})=\sum_{\mathrm{A}}^{\mathrm{N}} \frac{\mathrm{Z}_{\mathrm{A}}}{\left|\mathbf{R}_{\mathrm{A}}-\mathbf{r}\right|}-\int \frac{\rho\left(\mathbf{r}^{\prime}\right)}{\left|\mathbf{r}^{\prime}-\mathbf{r}\right|} d^{3} \mathbf{r}^{\prime}$

where, $\mathrm{Z}_{\mathrm{A}}$ denotes the charge of the nucleus $\mathrm{A}$ located at $\mathbf{R}_{\mathrm{A}}$ and $\rho(\mathbf{r})$ is the molecular electronic charge density. The first and second terms on the r.h.s. of the equation Eq. (1) represent the nuclear and electronic contributions respectively. Three-dimensional information regarding a scalar field is provided by its topographical analysis. ${ }^{50}$ MESP calculations and topographical analysis of all the BQS and related molecules have been carried out by employing the optimized gas phase geometries through the INDPROP ${ }^{50}$ program. The present level of theory is known to be adequate for MESP topographical analysis. ${ }^{51-53}$ The deep negative-valued MESP minima of BQS, representing the strongest electron localization regions, are considered as anchoring points for the $\mathrm{Li}^{+}$cation. Frequency calculations are done for all the optimized geometries of $\mathrm{BQS}$ and $\mathrm{BQS} \cdots \mathrm{Li}^{+}$complexes for confirming the minimal nature of optimized geometries on the potential energy surfaces. The contribution of functions corresponding to higher multiplicity states (expectation values $<\mathrm{S}^{2}>$ ), was found to be negligible for all the open shell (radicals) BQS studied in this work. The binding energy $(\Delta \mathrm{E})$ of a BQS is calculated as per the usual definition, viz.,

$\Delta \mathrm{E}=\mathrm{E}\left(\mathrm{BQS} \cdots \mathrm{Li}^{+}\right)-\left[\mathrm{E}(\mathrm{BQS})+\mathrm{E}\left(\mathrm{Li}^{+}\right)\right]$

where, $\mathrm{E}\left(\mathrm{BQS} \cdots \mathrm{Li}^{+}\right), \mathrm{E}(\mathrm{BQS})$ are the energies of fully optimized $\mathrm{BQS} \cdots \mathrm{Li}^{+}$complex, BQS, respectively, and $\mathrm{E}\left(\mathrm{Li}^{+}\right)$ is the energy of the $\mathrm{Li}^{+}$ion. MESP features of BQS and optimized geometries of $\mathrm{BQS} \cdots \mathrm{Li}^{+}$complexes are visualized using UNIVIS ${ }^{54}$ and GuassView 5.0 packages, respectively. The basis set superposition error (BSSE)-corrected binding energies are also calculated using counterpoise correction method. ${ }^{55}$

To obtain a more realistic picture of the process of proton transfer to quinone as a function of its reduced state in bacterial photosynthetic reaction center, interaction of the reduced states of BQS with motifs of protonated Serine (SER) and Histidine (HIS) as well as with $\mathrm{NH}_{4}^{+}$are explored. The binding energies are calculated at the optimized complex geometries of BQS with SER, HIS and $\mathrm{NH}_{4}^{+}$with frozen monomers, i.e., at the geometries in the optimized complex. Furthermore, BSSE-corrected binding energies are also calculated. The role of dispersion forces in complex formation is explored by employing M06-2X functional. ${ }^{56}$

Further, the electron conductivity switching behavior through the 9,10-benzoanthraquinone and its reduced and protonated state viz., $\mathrm{QH}_{2}$ calculated by Seidel et al. ${ }^{23}$ is analyzed via the MESP topographical study. The CCP, i.e. a $(3,+1)$ saddle point connecting the negative MESP regions engulfing the minima, is explored for understanding the conductivity pattern.

\section{Results and Discussion}

The MESP features of BQ with its different reduction and protonation states are presented by the selected negative and positive MESP isosurfaces displayed in Figure 2. MESP minima, which are marked as dark blue dots, highlight the electron localization regions for these states. In Figure 2, a positive-valued meshwire isosurface is also shown for highlighting the nuclear framework.

p-Benzoquinone (BQ): The three MESP isosurfaces of values -25.1 (blue), 3.1 (yellow) and 431.7 (red meshwire) $\mathrm{kcal} \mathrm{mol}^{-1}$ for $\mathrm{BQ}$ are shown in Figure 2(a). Here, the negative-valued regions indicate prominent electronic charge localization around the oxygen atoms. The MESP value of four (symmetric) minima, which are engulfed by blue isosurfaces is $-38.8 \mathrm{kcal} \mathrm{mol}^{-1}$. These minima are situated in the molecular plane, about 1.37 


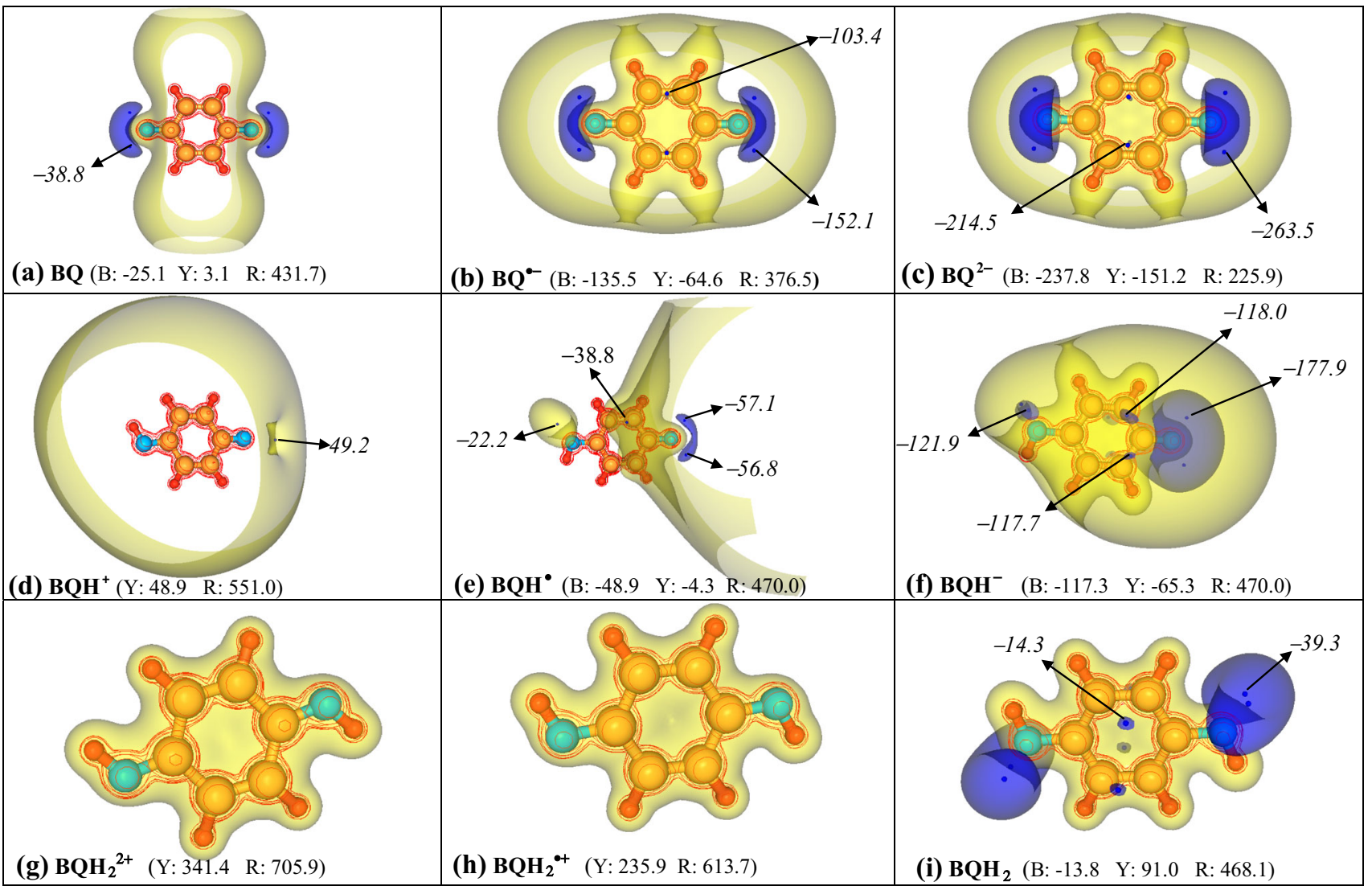

Figure 2. The MESP features of BQ in different reduction and protonation states with the selected negative and positive MESP isosurfaces (blue (B), yellow (Y) and red (R)). The values of MESP minima are denoted in italics. MESP values are in $\mathrm{kcal} \mathrm{mol}^{-1}$. See text for details.

$\AA$ away from the respective oxygen atoms. These minima are also seen in the two dimensional (2D) contour diagram of BQ in molecular plane given in Figure 3(a).

$p$-Benzosemiquinone radical anion $\left(\mathrm{BQ}^{\bullet-}\right)$ : Figure 2 (b) reveals the negative regions of $\mathrm{BQ}^{\bullet-}$ to be much more negative than those of $\mathrm{BQ}$. The complete molecule of $\mathrm{BQ}^{\bullet-}$ is covered by a negative-valued MESP sheath. The MESP minima of the oxygens at UB3LYP calculation exhibit a large reduction in the value, viz., $-152.1 \mathrm{kcal} \mathrm{mol}^{-1}$, approximately 3.9 times those for BQ and located at $1.23 \AA$ away from the oxygen ( $c f$. Figure 3(b) for $2 \mathrm{D}$ contours). The MESP values of $\mathrm{C}=\mathrm{C}$ bond minima present above the ring of $\mathrm{BQ}^{\bullet-}$ (as seen in Figure 2(b)) are $-103.4 \mathrm{kcal} \mathrm{mol}^{-1}$ and they are located about $1.62 \AA$ above the ring plane in the respective $\mathrm{C}=\mathrm{C}$ bond region.

p-Benzoquinone dianion $\left(\mathbf{Q}^{2-}\right)$ : The highly negative character of $\mathrm{BQ}^{2-}$ compared to $\mathrm{BQ}$ and $\mathrm{BQ}^{\bullet-}$ is conspicuous from Figure 2(c). The MESP minima values of oxygen and $\mathrm{C}=\mathrm{C}$ bond show a dramatic reduction and turn out to be -263.5 and $-214.5 \mathrm{kcal} \mathrm{mol}^{-1}$, about $1.17 \AA$ away from the oxygen atom and $1.47 \AA$ at a perpendicular distance above the ring plane, respectively.
It is also reflected in Figure 3(c) that depicts the 2D MESP contours in molecular plane of $\mathrm{BQ}^{2-}$. The oxygen MESP minimum value of $\mathrm{BQ}^{2-}$ is 6.79 times that for $\mathrm{BQ}$.

p-Benzosemiquinone cation $\left(\mathrm{BQH}^{+}\right)$: The characteristic MESP distribution of $\mathrm{BQH}^{+}$is shown in Figure 2(d) wherein the complete molecule is covered with a positive-valued MESP isosurface. Only one positive valued (i.e., $49.2 \mathrm{kcal} \mathrm{mol}^{-1}$ ) MESP minimum is observed for this state at a distance of $1.78 \AA$ from the carbonyl oxygen. These observations emphasize the electrophilic nature of $\mathrm{BQH}^{+}$state, as may be intuitively expected from its cationic nature.

p-Benzosemiquinone radical $\left(\mathbf{B Q H}^{\bullet}\right)$ : This molecule shows negative-valued MESP patches around it ( $c f$. Figure 2(e)). More negative charge is localized near the carbonyl oxygen region than the hydroxyl oxygen region. The hydroxyl oxygen MESP minimum is $-22.2 \mathrm{kcal} \mathrm{mol}^{-1}$ located about $1.32 \AA$ from it. MESP minima of carbonyl oxygen are deeper than those of neutral BQ possessing values of -57.1 and $-56.8 \mathrm{kcal} \mathrm{mol}^{-1}$ at a distance of $1.33 \AA$ from the oxygen atom. The MESP minima of carbonyl oxygen region 


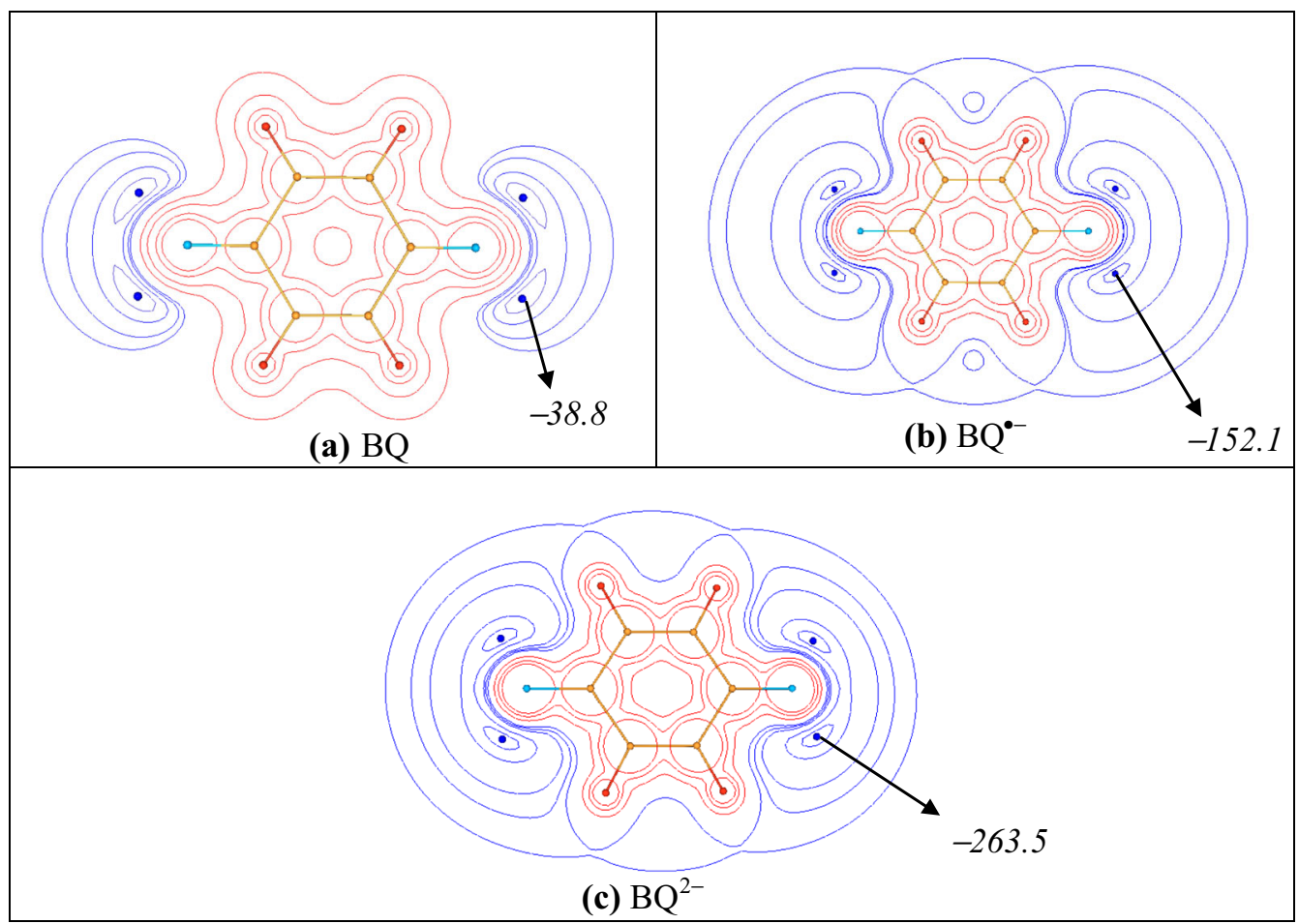

Figure 3. 2D MESP contours (values are given from inside out and in $\mathrm{kcal} \mathrm{mol}^{-1}$ ) (R:red contours are positive and B:blue are negative) of, (a) BQ (R: 947.54, 455.57, 152.48, 45.18 and $\mathrm{B}:-35.77,-29.49,-20.71,-15.06)$; (b) $\mathrm{BQ}^{\bullet-}(\mathrm{R}: 673.32,263.55,58.36$ and $\mathrm{B}$ : $-148.09,-133.66,-101.03,-71.54,-64.01)$; and (c) $\mathrm{BQ}^{2-}(\mathrm{R}: 480.04,208.33,5.65$ and $\mathrm{B}$ : $-257.28,-240.34,-196.41,-173.19,-149.35)$. The respective oxygen minima are shown by blue dots.

are deeper by a factor of $\sim 2.6$ than those of hydroxyl oxygen.

p-Benzosemiquinone anion $\left(\mathbf{B Q H}^{-}\right)$: The observed MESP values here are deeper than those for $\mathrm{BQH}^{\bullet}$ (cf. Figure 2(f)). The MESP minima of carbonyl and hydroxyl oxygens are -177.9 and $-121.9 \mathrm{kcal} \mathrm{mol}^{-1}$, respectively, and are located 1.16 and $1.23 \AA$ away from them. This shows that the carbonyl oxygen of $\mathrm{BQH}^{-}$ is more nucleophilic than the hydroxyl one. Minima of the carbonyl and hydroxyl oxygens in $\mathrm{BQH}^{-}$are about 3.13 and 5.49 times more pronounced as compared with their counterparts in $\mathrm{BQH}^{\bullet}$.

Hydroquinone dication $\left(\mathrm{BQH}_{2}^{2+}\right)$ : The negative MESP region is conspicuous by its absence for $\mathrm{BQH}_{2}^{2+}(c f$. Figure $2(\mathrm{~g})$ ) and not a single negative MESP minimum is found for this cationic species. This highlights highly electrophilic behavior of $\mathrm{BQH}_{2}^{2+}$ molecule.

Hydroquinone radical cation $\left(\mathrm{BQH}_{2}^{\circ+}\right)$ : For this state also, no negative-valued MESP region is noticed ( $c f$. Figure 2(h)).

Hydroquinone $\left(\mathbf{B Q H}_{\mathbf{2}}\right)$ : This state shows negative MESP islands, along with a pair of MESP minima for each oxygen (see Figure 2(i)) at $-39.3 \mathrm{kcal} \mathrm{mol}^{-1}$ situated about $1.28 \AA$ away from it. On the other hand, the minima, above and below the ring plane and perpendicular to $\mathrm{C}=\mathrm{C}$ bonds possessing a value of $-14.3 \mathrm{kcal} \mathrm{mol}^{-1}$, lie $1.87 \AA$ above the ring plane. Thus, the MESP distributions of $\mathrm{BQ}$ and $\mathrm{BQH}_{2}$ are seen to differ to some extent.

In summary, the carbonyl or hydroxyl oxygen regions of all the non-cationic states possess pronounced negative MESP values. These values become more negative with the trends observed in going from $\mathrm{BQ} \rightarrow \mathrm{BQ}^{\bullet-} \rightarrow$ $\mathrm{BQ}^{2-}, \mathrm{BQH}^{+} \rightarrow \mathrm{BQH}^{\bullet} \rightarrow \mathrm{BQH}^{-}$and $\mathrm{BQH}_{2}^{2+} \rightarrow$ $\mathrm{BQH}_{2}^{\circ} \rightarrow \mathrm{BQH}_{2}$ with the addition of an electron in each step. A noteworthy observation is that the carbonyl oxygen regions for the singly protonated states, $\mathrm{BQH}^{\circ}$ and $\mathrm{BQH}^{-}$, are more electron rich than the respective hydroxyl counterparts. It is also noticed that the cationic states viz., $\mathrm{BQH}^{+}, \mathrm{BQH}_{2}^{\bullet+}$ and $\mathrm{BQH}_{2}^{2+}$ have only positive MESP around them, establishing their electrophilic identity. On the other hand, anionic states, viz., $\mathrm{BQ}^{2-}$, $\mathrm{BQ}^{\bullet-}$ and $\mathrm{BQH}^{-}$are engulfed by a negative MESP sheath around them showing their nucleophilic nature. These observations are in accordance with the theorem proved by Pathak and Gadre ${ }^{57}$ regarding the zero flux 


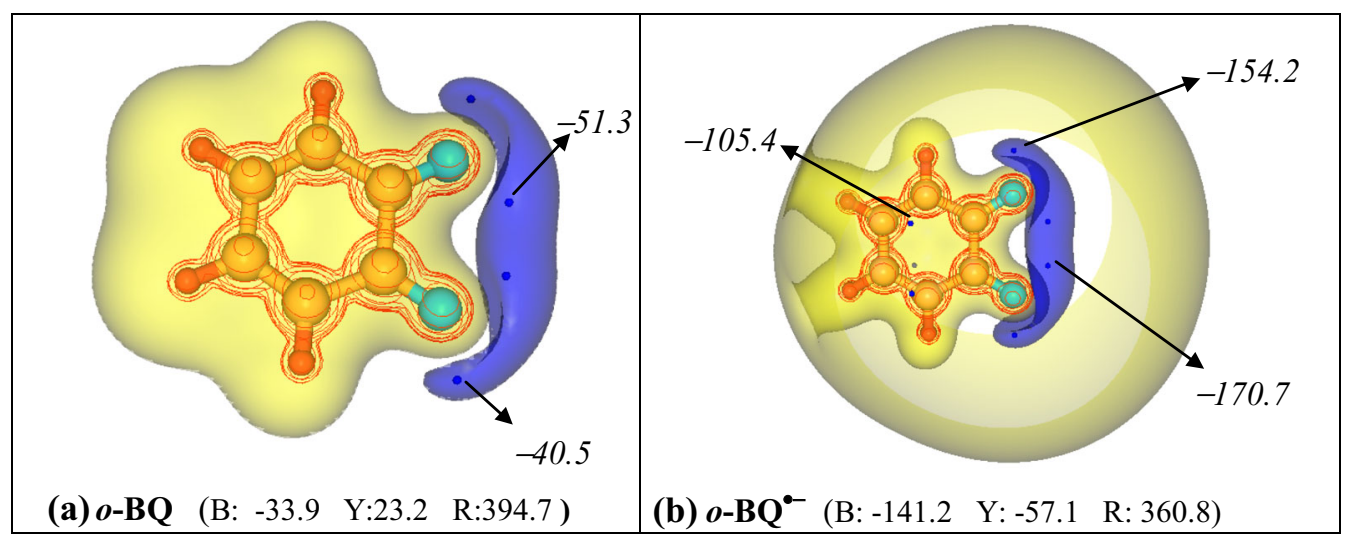

Figure 4. MESP isosurfaces (blue (B), yellow (Y) and red (R)) and minima of $o$-BQ and $o-\mathrm{BQ}^{\bullet-}$. The values of MESP minima are denoted in italics. MESP values are in $\mathrm{kcal} \mathrm{mol}^{-1}($ See text for details.)

surface for anions. Another significant observation is that the protonation of a particular BQ state increases the MESP values of the regions more positive making it less nucleophilic or more electrophilic moiety. This behavior is observed for $\mathrm{BQ} \rightarrow \mathrm{BQH}^{+} \rightarrow \mathrm{BQH}_{2}^{2+}, \mathrm{BQ}^{\bullet-} \rightarrow$ $\mathrm{BQH}^{\bullet} \rightarrow \mathrm{BQH}_{2}^{\bullet+}$ and $\mathrm{BQ}^{2-} \rightarrow \mathrm{BQH}^{-} \rightarrow \mathrm{BQH}_{2}$ states.

We have also performed MESP topographical analysis on a topological isomer of para-BQ i.e. orthobenzoquinone $(o-\mathrm{BQ})$ and its radical semiquinone anion $\left(o-\mathrm{BQ}^{\bullet-}\right)$, as another test case that has been studied by Nepal et al. ${ }^{17}$ The MESP isosurfaces with respective minima of $o$-BQ and $o$-BQ ${ }^{\bullet-}$ are shown in the Figure 4(a) and (b), respectively. The most negative MESP minimum is observed near carbonyl oxygen of $o-\mathrm{BQ}$ having value $-51.3 \mathrm{kcal} \mathrm{mol}^{-1}$, indicating the more electron localization (see Figure 4(a)). However, in the case of $o-\mathrm{BQ}^{\bullet-}$ the most negative MESP minimum also observed in carbonyl oxygen region shows the value of $-170.7 \mathrm{kcal} \mathrm{mol}^{-1}$ which is deeper by a factor of about 3.3 than that observed for $o$-BQ.

As shown by Nepal et al., ${ }^{17}$ a cationic species viz., $\mathrm{CNH}_{2}\left(\mathrm{NHCH}_{3}\right)_{2}^{+}$forms a complex with $o$-BQ. The deeper negative electronic region of $o-\mathrm{BQ}^{\bullet-}$, around the oxygen atom, than that in $o$-BQ supports the reported higher binding energy ( $\sim 2.1$ times) of cationic species with $o-\mathrm{BQ}^{\bullet-}$ than the latter one. We have verified this by the calculation of $\Delta \mathrm{E}$ via Eq. (2) for electrophilic $\mathrm{Li}^{+}$ binding.

These cation binding interactions may be considered as a prototype for the aforementioned interactions of ubiquinone redox states with the surrounding protonated amino acids in the photosynthetic RC.

Negative MESP minima are used as the binding sites for $\mathrm{Li}^{+}$. The $\Delta \mathrm{E}$ value (via Eq. (2)) for $o$ $\mathrm{BQ} \cdots \mathrm{Li}^{+}$complex is observed at $-60.97 \mathrm{kcal} \mathrm{mol}^{-1}$, when $\mathrm{Li}^{+}$is placed in the vicinity of the carbonyl oxygen lone pair. However, the $\Delta \mathrm{E}$ value turns out to be
$-172.67 \mathrm{kcal} \mathrm{mol}^{-1}$, for $o-\mathrm{BQ}^{\bullet-} \ldots \mathrm{Li}^{+}\left(\mathrm{Li}^{+}\right.$bonded at carbonyl oxygen binding site) complex which is 2.8 times more favourable than $o-\mathrm{BQ} \cdots \mathrm{Li}^{+}$. This increase in $\Delta \mathrm{E}$ value for the complex of $o-\mathrm{BQ}^{\bullet-}$ state with $\mathrm{Li}^{+}$is also reflected in cation binding energies to this anionic state than $o-\mathrm{BQ}$ (4.3 times) noticed by Nepal $e t$ $a l .{ }^{17}$

Keeping the above in mind, a complete picture of the electronic distribution in reduction and protonation states of BQ is further confirmed with the interaction of a test electrophile, viz., $\mathrm{Li}^{+}$, in terms of the respective binding energies, $\Delta \mathrm{E}$. The corresponding optimized structures along with their $\mathrm{Li}^{+}$binding distances are shown in Figure 5. The calculated $\Delta$ Es of these fully optimized $\mathrm{BQS} \cdots \mathrm{Li}^{+}$complexes are reported in Table 1 . The negative MESP minima are observed near the $\mathrm{C}=\mathrm{C}$, carbonyl as well as the hydroxyl oxygen regions of $\mathrm{BQS}$ indicating stronger electron localization. These features are utilized for generating the initial guess structures of $\mathrm{BQS} \cdots \mathrm{Li}^{+}$complexes. As $\mathrm{BQH}^{+}, \mathrm{BQH}_{2}^{2+}$ and $\mathrm{BQH}_{2}^{\circ+}$ are immersed in positive MESP isosurfaces with no negative MESP minima, these BQS are not considered for calculation of binding energies with $\mathrm{Li}^{+}$. The $\Delta \mathrm{E}$ values of $\mathrm{Li}^{+}$with $\mathrm{BQ}$ are observed as $-43.83 \mathrm{kcal} \mathrm{mol}^{-1}$ at carbonyl oxygen binding site (Figure 5a) and $-9.17 \mathrm{kcal} \mathrm{mol}^{-1}$ above the ring plane (Figure 5b). The MESP minimum for $\mathrm{BQ}^{\bullet-}$ is substantially more negative and as a consequence, $\Delta \mathrm{E}$ of $\mathrm{BQ}^{\bullet-} \cdots \mathrm{Li}^{+}$complex is observed to be more favourable. The values for $\Delta \mathrm{Es}$ of $\mathrm{BQ}^{-} \ldots \mathrm{Li}^{+}$ complex are $-139.58 \mathrm{kcal} \mathrm{mol}^{-1}$ at carbonyl oxygen binding site and $-126.15 \mathrm{kcal} \mathrm{mol}^{-1}$ above the ring plane. It can also be noticed that the $\Delta \mathrm{E}$ values observed for $o$-BQ $\cdots \mathrm{Li}^{+}$and $o-\mathrm{BQ}^{\bullet-} \ldots \mathrm{Li}^{+}$are more prominent than those observed for $\mathrm{BQ} \cdots \mathrm{Li}^{+}$and $\mathrm{BQ}^{\bullet-} \ldots \mathrm{Li}^{+}$, in line with more negative values of the respective MESP minima for the $o$-benzoquinone states 


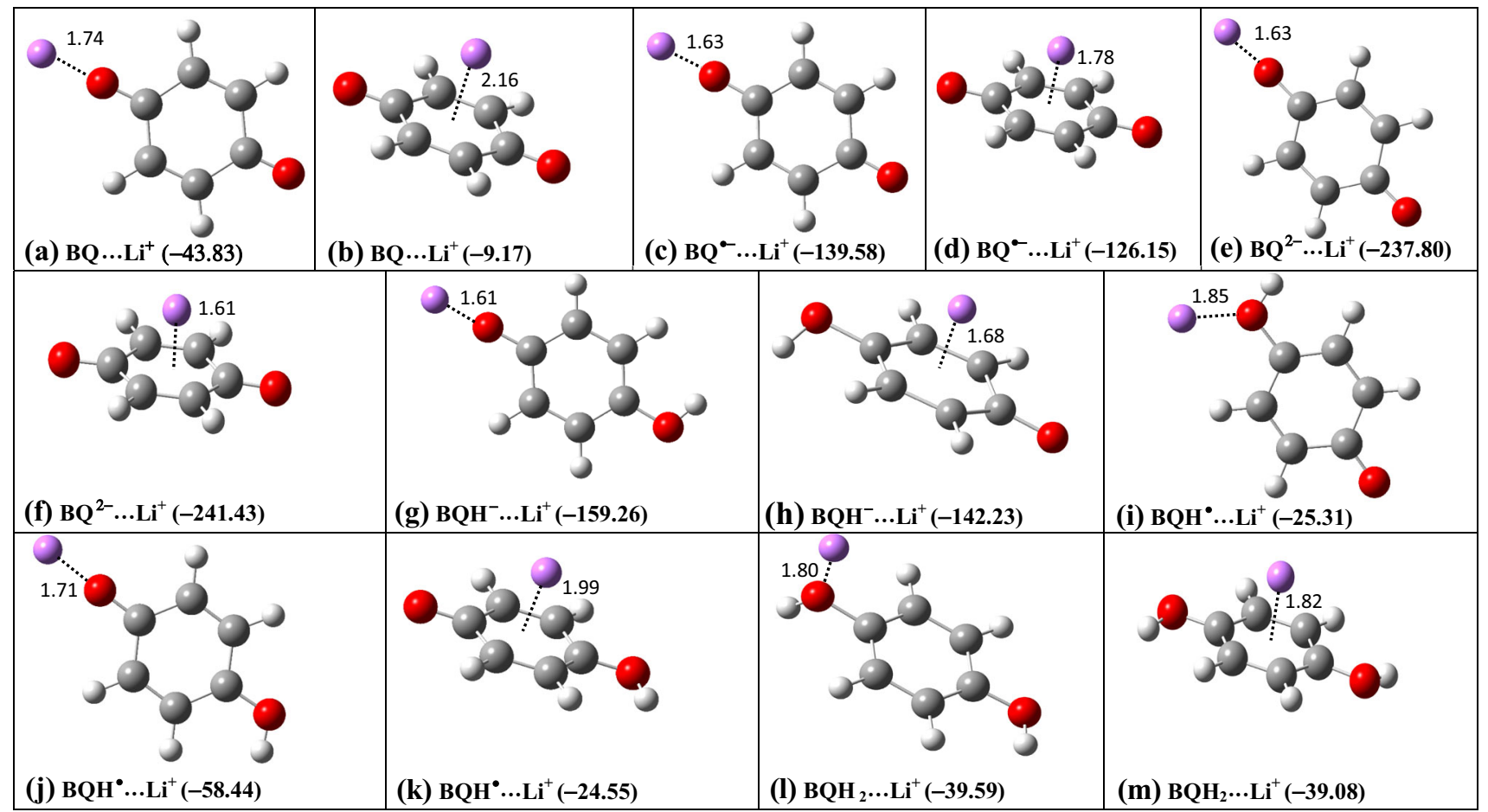

Figure 5. The minimum energy structures of $\mathrm{BQS} \cdots \mathrm{Li}^{+}$complexes. The values in brackets are respective binding energies of BQS $\cdots \mathrm{Li}^{+}$complexes in $\mathrm{kcal} \mathrm{mol}^{-1}$. The values near to the dotted lines are distances of $\mathrm{Li}^{+}$from respective position in $\AA$. See text and Table 1 for details.

Table 1. Calculated binding energies with full optimized monomers $(\Delta \mathrm{E})$, binding energy at the optimized complex geometry with frozen monomers $\left(\Delta \mathrm{E}^{\mathrm{FM}}\right)$ and BSSE-corrected binding energies $\left(\Delta \mathrm{E}^{\mathrm{BSSE}}\right), \mathrm{V}_{\min }$ and distances of Li $\mathrm{i}^{+}$from respective positions of different reduction and protonation states of $p$-benzoquinone with $\mathrm{Li}^{+}$using B3LYP/6-311+G(d,p) level of theory.

\begin{tabular}{|c|c|c|c|c|c|c|c|}
\hline State & Position $^{\mathrm{a}}$ & $\mathrm{V}_{\min }\left(\mathrm{kcal} \mathrm{mol}^{-1}\right)$ & $\mathrm{d}_{\min }(\AA)$ & $\mathrm{d}_{\mathrm{Li}+}(\AA)$ & $\Delta \mathrm{E}\left(\mathrm{kcal} \mathrm{mol}^{-1}\right)$ & $\Delta \mathrm{E}^{\mathrm{FM}}\left(\mathrm{kcal} \mathrm{mol}^{-1}\right)$ & $\Delta \mathrm{E}^{\mathrm{BSSE}}\left(\mathrm{kcal} \mathrm{mol}^{-1}\right)$ \\
\hline \multirow[t]{2}{*}{ BQ } & $-\mathrm{O}$ & -38.86 & 1.37 & 1.74 & -43.83 & -44.81 & -44.20 \\
\hline & ARP & - & - & 2.14 & -9.17 & -9.70 & -8.91 \\
\hline \multirow[t]{2}{*}{$\mathrm{BQ}^{\bullet-}$} & $-\mathrm{O}$ & -152.08 & 1.23 & 1.63 & -139.58 & -141.02 & -140.44 \\
\hline & ARP & -103.41 & 1.61 & 1.76 & -126.15 & -126.70 & -125.89 \\
\hline \multirow[t]{2}{*}{$\mathrm{BQ}^{2-}$} & $-\mathrm{O}$ & -263.47 & 1.17 & 1.63 & -237.80 & -240.46 & -216.40 \\
\hline & ARP & -214.52 & 1.47 & 1.61 & -241.43 & -243.11 & -224.32 \\
\hline \multirow[t]{3}{*}{$\mathrm{BQH}^{\bullet}$} & $-\mathrm{O}$ & $\begin{array}{l}-57.12 \\
-56.77\end{array}$ & 1.33 & 1.71 & -58.44 & -59.26 & -58.67 \\
\hline & $-\mathrm{OH}$ & -22.19 & 1.32 & 1.85 & -25.31 & -26.88 & -26.06 \\
\hline & ARP & -4.28 & 2.09 & 1.96 & -24.55 & -25.29 & -24.53 \\
\hline \multirow[t]{2}{*}{$\mathrm{BQH}^{-}$} & $-\mathrm{O}$ & -177.9 & 1.16 & 1.61 & -159.26 & -161.86 & -161.26 \\
\hline & ARP & -118.04 & 1.62 & 1.71 & -142.23 & -143.61 & -142.79 \\
\hline \multirow{2}{*}{$\mathrm{BQH}_{2}$} & $-\mathrm{OH}$ & -39.29 & 1.23 & 1.80 & -39.59 & -43.52 & -42.57 \\
\hline & ARP & -14.26 & 1.87 & 1.85 & -39.08 & -40.31 & -39.55 \\
\hline
\end{tabular}

a-O: Carbonyl oxygen, -OH: hydroxyl oxygen and ARP: from the ring plane (See Figure 4 for details).

$\mathrm{V}_{\min }$ : Most negative valued MESP minimum.

$\mathrm{d}_{\text {min }}$ : Distance of MESP minimum from the carboxyl/hydroxyl oxygen or above the ring plane.

$\mathrm{d}_{\mathrm{Li}+}$ : Perpendicular distance of $\mathrm{Li}^{+}$from the ring centre.

than those of $p$-benzoquinone. Addition of another electron to $\mathrm{BQ}^{\bullet-}$ further deepens the MESP minimum values as a result of more electron localisation at carbonyl oxygen as well as $\mathrm{C}=\mathrm{C}$ regions and it is reflected in more favourable $\Delta \mathrm{E}$ than the BQ having values at $-237.80 \mathrm{kcal} \mathrm{mol}^{-1}$ at carbonyl oxygen and $-241.43 \mathrm{kcal} \mathrm{mol}^{-1}$ above the ring plane (cf. Table 1) 


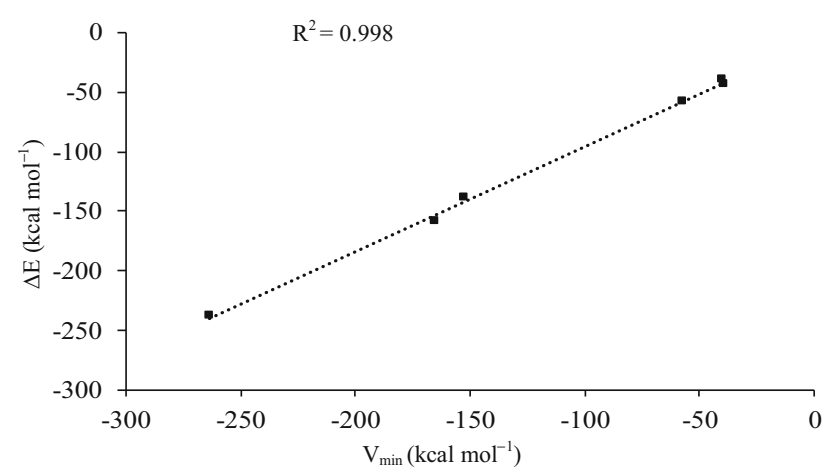

Figure 6. Correlation between value of most negative MESP minimum $\mathrm{V}_{\text {min }}$ and the corresponding $\mathrm{Li}^{+}$binding energy $(\Delta \mathrm{E})$ of BQS. See text for details.

Further, it is observed that addition of an electron and a proton to $\mathrm{BQ}$, i.e., $\mathrm{BQH}^{\bullet}$ state follows the trend going from more negative than the $\mathrm{BQ}$ one MESP minimum values at carbonyl (which is having most negative MESP minimum value) towards more positive side at the hydroxyl oxygen and then above the ring in $\mathrm{C}=\mathrm{C}$ regions. The respective calculated $\Delta$ Es are $-58.44,-25.31$ and $-24.55 \mathrm{kcal} \mathrm{mol}^{-1}$ for $\mathrm{BQH}^{\bullet} \cdot \mathrm{Li}^{+}$complexes. However, for the reduced state $\mathrm{BQH}^{-} \cdots \mathrm{Li}^{+}$, the $\Delta \mathrm{E}$ is more enhanced to $-159.26 \mathrm{kcal} \mathrm{mol}^{-1}$ at carbonyl oxygen position and then above the ring in $\mathrm{C}=\mathrm{C}$ region $\left(-142.23 \mathrm{kcal} \mathrm{mol}^{-1}\right.$ For $\mathrm{BQH}_{2} \cdots \mathrm{Li}^{+}$complexes, $\Delta \mathrm{Es}$ are observed to be -39.59 and $-39.08 \mathrm{kcal} \mathrm{mol}^{-1}$ at hydroxyl oxygen and above the ring site respectively. From calculated $\triangle \mathrm{E}$ of BQS $\cdots \mathrm{Li}^{+}$complexes, it is noticed that the carbonyl oxygen is the more favourable site for $\mathrm{Li}^{+}$binding and it is also reflected from respective MESP minima values. A remarkable correlation between the MESP minimum values and the respective $\mathrm{Li}^{+}$binding energies of all the non-cationic BQS is observed as given in Figure 6, with a correlation coefficient $\left(\mathrm{R}^{2}\right)$ of 0.998 . The BSSE corrected binding energies ( $c f$. Table 1) also turn out to be in good agreement with $\triangle \mathrm{E}$ and show correlation coefficient 0.995 with MESP minimum values.

Furthermore, we have assessed the interactions of $\mathrm{BQ}$ and its reduction states $\mathrm{BQ}^{\bullet-}$ and $\mathrm{BQ}^{2-}$ with two model systems, viz., SER and HIS, mimicking the realistic interacting systems observed in photosynthetic reaction centre interacting with the ubiquinone for proton transfer processes. ${ }^{10}$ More electron localized regions of the states near the oxygen lone pair obtained with deepest MESP minima are chosen to assess these interactions. ${ }^{58}$ The minimum energy structures of the complexes BQS $\cdots$ SER and BQS ... HIS are depicted in Figure 7.
The binding energies for SER with BQ and $\mathrm{BQ}^{\bullet-}$, respectively, (see Table 2) are -5.66 and -14.30 $\mathrm{kcal} \mathrm{mol}^{-1}$, where the proton transfer from SER to $\mathrm{BQ}$ is not observed. However, the proton transfer is observed from SER to carbonyl oxygen of $\mathrm{BQ}^{2-}$ in the $\mathrm{BQ}^{2-} \ldots$ SER complex formation ( $c f$. Figure 7) with the binding energy $-111.71 \mathrm{kcal} \mathrm{mol}^{-1}$. The noticeably higher binding energy of $\mathrm{BQ}^{2-}$ with SER than that of $\mathrm{BQ}$ and $\mathrm{BQ}^{\bullet-}$ is attributed to the proton transfer in the complex. Similarly BQ and $\mathrm{BQ}^{\bullet-}$ interacting with HIS show binding energies of -4.62 and $-20.52 \mathrm{kcal} \mathrm{mol}^{-1}$, respectively, without proton transfer. In this case also, the proton transfer is observed in doubly reduced state of $\mathrm{BQ}$ from $\mathrm{HIS}$ to carbonyl oxygen of $\mathrm{BQ}^{2-}$ in $\mathrm{BQ}^{2-}$...HIS complex formation (see Figure 7) with binding energy $-166.54 \mathrm{kcal} \mathrm{mol}^{-1}$. This suggests that only single reduction of $\mathrm{BQ}$ is not sufficient to transfer a proton from the amino acids. However, with the source of higher $\mathrm{H}^{+}$population connected through proton transfer pathways through protonated amino acids and hydronium ions to the quinone moiety in photosynthetic reaction center may transfer the proton to singly reduced state, $\mathrm{BQ}^{\bullet-}$. To verify the latter conjecture, the interaction of a highly proton donating cation, i.e. $\mathrm{NH}_{4}^{+}$ with BQ systems is also studied.

The neutral state, BQ shows $-24.89 \mathrm{kcal} \mathrm{mol}^{-1}$ binding energy with $\mathrm{NH}_{4}^{+}$complex. The remarkable observation is that in case of $\mathrm{BQ}^{--} \cdots \mathrm{NH}_{4}^{+}$and $\mathrm{BQ}^{2-} \cdots \mathrm{NH}_{4}^{+}$ complexes, proton transfer take place from $\mathrm{NH}_{4}^{+}$to the carbonyl oxygen of $\mathrm{BQ}^{\bullet-}$ and $\mathrm{BQ}^{2-}$ with binding energies -215.87 and $-397.96 \mathrm{kcal} \mathrm{mol}^{-1}$, respectively. The BSSE correction in binding energies is negligible for the complexes of $\mathrm{BQ}, \mathrm{BQ}^{\bullet-}$ with SER, HIS and $\mathrm{NH}_{4}^{+}$, whereas it is somewhat larger for the respective $\mathrm{BQ}^{2-}$ complexes (see Table 2). However, the same increasing binding energy trend is observed with BSSE correction for all the above complexes ( $c f$. Table 2) as that with uncorrected ones. The impact of dispersion effect on the binding energies calculated by employing M06-2X functional is observed to be less prominent but shows consistent increasing trend with B3LYP functional.

The study shows that the SER and HIS interact with carbonyl oxygen of $\mathrm{BQ}$, the neutral state, via weak intermolecular $\mathrm{H}$-bonding and similar kinds of features are also observed for anionic $\mathrm{BQ}^{\bullet-}$ state. When $\mathrm{BQ}$ accepts two electron and becomes dianion i.e. $\mathrm{BQ}^{2-}$, the negative MESP at its carbonyl oxygen becomes more susceptible to accept proton from HIS as well as SER. But in case of BQS.... $\mathrm{NH}_{4}^{+}$complexes, BQ shows hydrogen bonding interaction with $\mathrm{NH}_{4}^{+}$, however, anionic $\mathrm{BQ}^{\bullet-}$ and $\mathrm{BQ}^{2-}$ states abstract protons from donor $\mathrm{NH}_{4}^{+}$. 


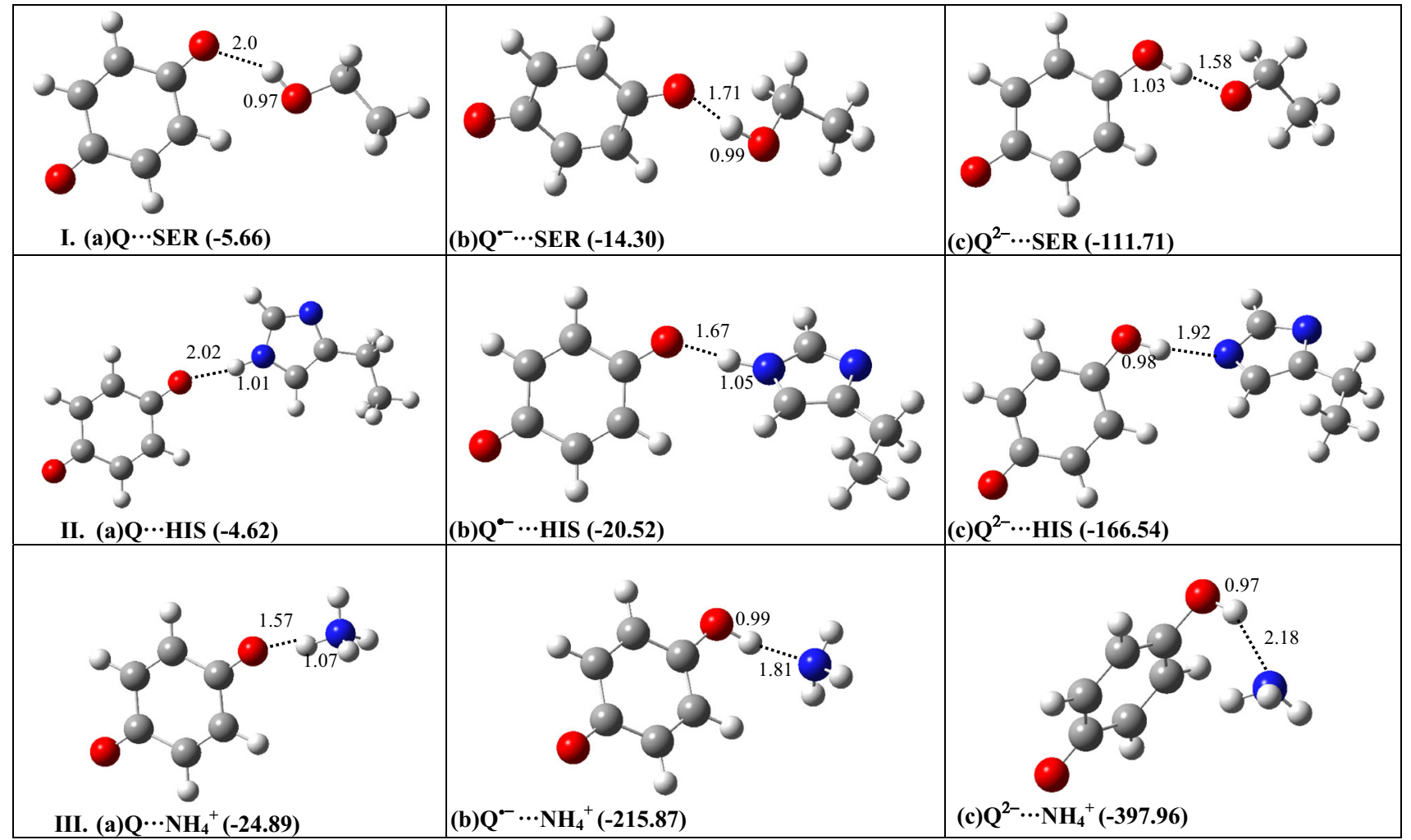

Figure 7. The minimum energy structures of, I) BQS $\cdots$ SER II) BQS $\cdots$ HIS and III) BQS $\cdots$ NH N $_{4}^{+}$complexes. The respective $\mathrm{H}$-bond lengths are given in $\AA$ and values in the brackets are binding energies. i.e., $\Delta \mathrm{E}^{\mathrm{FM}}$ values of respective complex.

Table 2. Calculated binding energies $\left(\Delta \mathrm{E}^{\mathrm{FM}}\right)$ in $\mathrm{kcal} \mathrm{mol}^{-1}$ of optimized geometries of complexes of SER, HIS and NH ${ }_{4}^{+}$ with reduction states of $p$-benzoquinone viz., $\mathrm{BQ}, \mathrm{BQ}^{\bullet-}$ and $\mathrm{BQ}^{2-}$ using B3LYP/6-311+G(d,p) level of theory. The $\Delta \mathrm{E}$ values calculated using M06-2X are shown in parentheses. $\triangle \mathrm{E}^{\mathrm{BSSE}}$ is the BSSE-corrected binding energy.

\begin{tabular}{|c|c|c|c|c|c|c|}
\hline \multirow[t]{2}{*}{ State } & \multicolumn{2}{|l|}{ SER } & \multicolumn{2}{|l|}{ HIS } & \multicolumn{2}{|l|}{$\mathrm{NH}_{4}^{+}$} \\
\hline & $\Delta \mathrm{E}^{\mathrm{FM}}$ & $\Delta \mathrm{E}^{\mathrm{BSSE}}$ & $\Delta \mathrm{E}^{\mathrm{FM}}$ & $\Delta \mathrm{E}^{\mathrm{BSSE}}$ & $\Delta \mathrm{E}^{\mathrm{FM}}$ & $\Delta \mathrm{E}^{\mathrm{BSSE}}$ \\
\hline BQ & $\begin{array}{l}-5.66 \\
(-7.27)\end{array}$ & -5.31 & $\begin{array}{l}-4.62 \\
(-5.20)\end{array}$ & -4.32 & $\begin{array}{l}-24.89 \\
(-24.31)\end{array}$ & -24.57 \\
\hline $\mathrm{BQ}^{\bullet-}$ & $\begin{array}{l}-14.30 \\
(-16.41)\end{array}$ & -13.77 & $\begin{array}{l}-20.52 \\
(-22.42)\end{array}$ & -20.08 & $\begin{array}{l}-215.87 \\
(-219.14)\end{array}$ & -215.51 \\
\hline $\mathrm{BQ}^{2-}$ & $\begin{array}{l}-111.71 \\
(-94.39)\end{array}$ & -106.29 & $\begin{array}{l}-166.54 \\
(-175.07)\end{array}$ & -154.97 & $\begin{array}{l}-397.96 \\
(-387.36)\end{array}$ & -370.14 \\
\hline
\end{tabular}

As mentioned earlier, the $\mathrm{AQ} / \mathrm{AQH}_{2}$ redox couple (Scheme 1) has proved to be promising component in molecular switches. ${ }^{18}$ Hence, it is important to analyse their electronic delocalization/conjugation as it plays an important role in electron conduction. ${ }^{21}$ As conjectured by Pingale, ${ }^{48}$ the $\mathrm{V}_{\mathrm{CCP}}$ values provide a quantitative measure for electronic conjugation present in a molecule. Here, we also correlate the quantitative strength of the conjugation represented by $\mathrm{V}_{\mathrm{CCP}}$ between the rings of the AQ and $\mathrm{AQH}_{2}$ states with their molecular electronic conductivity responsible for the switching mechanism. ${ }^{21}$ The MESP calculations are performed on $\mathrm{AQ}$ and $\mathrm{AQH} \mathrm{H}_{2}$ states of 9,10-anthraquinone $\pi$-conjugated with ethyne (see Scheme 1); i.e. the main spacer unit in redox active switches studied by Seidel et al. ${ }^{23}$

The MESP topographical features of $\mathrm{AQ}$ and $\mathrm{AQH}_{2}$ are shown in Figure 8. In AQ, each carbonyl oxygen (see Figure 8(a)) possess more negative MESP minima of values -38.6 and $-38.3 \mathrm{kcal} \mathrm{mol}^{-1}$ than its other regions. Moreover, the ethyne parts show ringlike isosurfaces containing four minima above and below the molecular plane of value $-12.0 \mathrm{kcal} \mathrm{mol}^{-1}$ connecting the minima of carbonyl oxygen through 
<smiles>C#Cc1ccc2c(c1)C(=O)c1ccc(C#C)cc1C2=O</smiles>

(a) AQ spacer

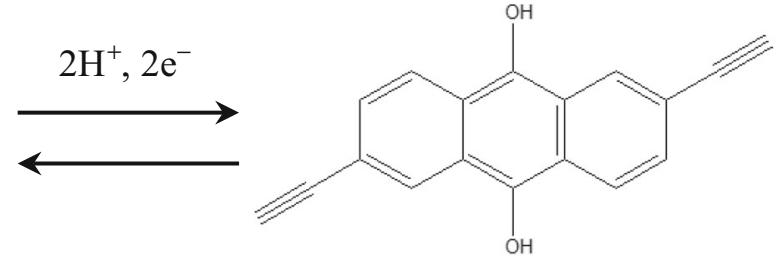

(b) $\mathrm{AQH} 2$ spacer

Scheme 1. Redox reaction of $A Q$ to $\mathrm{AQH}_{2}$ spacer units.

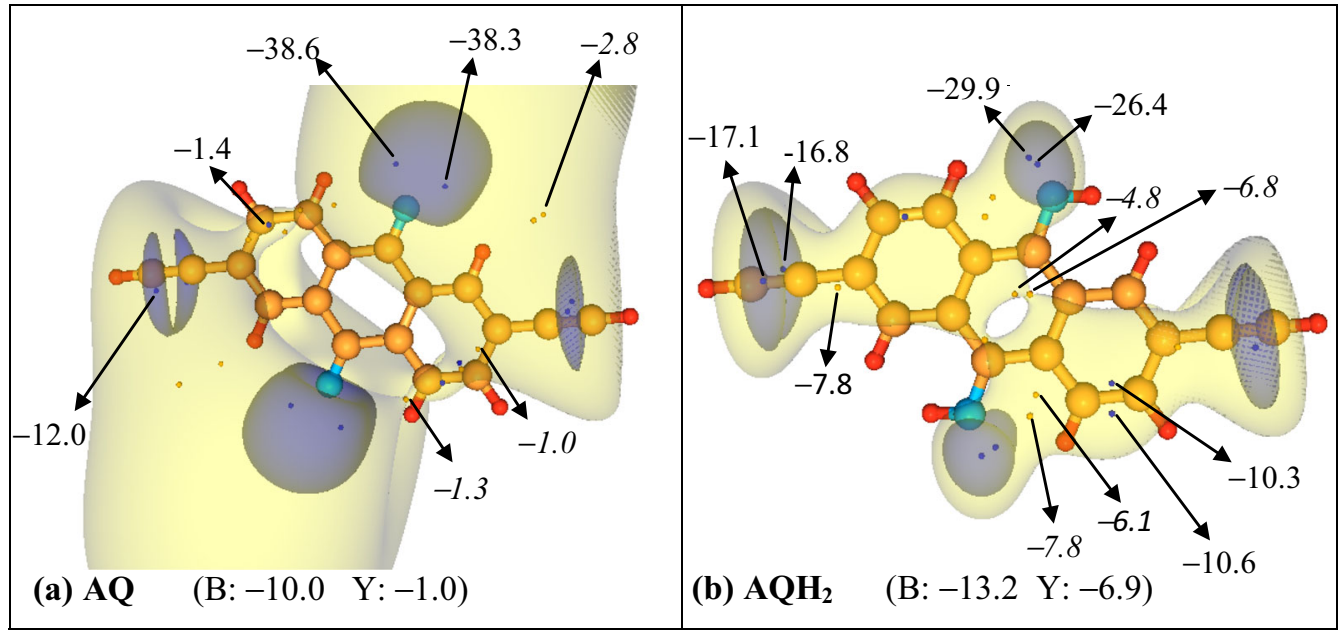

Figure 8. The selected MESP isosurfaces (blue (B), yellow (Y) and red (R)) of (a) AQ and (b) $\mathrm{AQH}_{2}$. The values of $\mathrm{V}_{C C P}$ are denoted in italics. MESP values are in $\mathrm{kcal} \mathrm{mol}^{-1}$. See text for details.

CCPs of value $-2.8 \mathrm{kcal} \mathrm{mol}^{-1}$. Four minima (values $-1.4 \mathrm{kcal} \mathrm{mol}^{-1}$ ) are observed near $\pi$-regions of $\mathrm{C}=\mathrm{C}$ bond of the side rings are $\sim 27$ times less negative than the minimum of the carbonyl oxygen and it suggests the large electronic localization of oxygen lone pairs. The $\mathrm{C}=\mathrm{C}$ bond minima are connected with the minima of carbonyl oxygen lone pairs through $(3,+1)$ saddle points of value $-1.3 \mathrm{kcal} \mathrm{mol}^{-1}$ ( $c f$. Figure $8(\mathrm{a})$ ). In case of $\mathrm{AQH}_{2}$, the carbonyl oxygen atoms possess two MESP minima of values -29.9 and $-26.4 \mathrm{kcal} \mathrm{mol}^{-1}$ (see Figure 8(b)).

Two minima of values, -10.6 and $-10.3 \mathrm{kcal} \mathrm{mol}^{-1}$ which are typically 7 times deeper than the corresponding minimum of $\mathrm{AQ}$ are present above and below the side rings. These side ring minima are connected with the ones of carbonyl oxygen lone pair electrons by $(3,+1)$ saddles of values -7.8 and $-6.1 \mathrm{kcal} \mathrm{mol}^{-1}$ that are $\sim 6$ times deeper than those of $\mathrm{AQ}$, which are absent in AQ ( $c f$. Figure 8(a) and (b)). The presence of central MESP CCPs is a signature of conjugation between $\pi$-regions of side rings of $\mathrm{AQH}_{2}$ (constructive interference) and attributed to its more electron conducting behaviour. The absence of central quinoid ring $\mathrm{CCP}$ connecting $\pi$-regions of side rings signifies lack of a $\pi$-conjugation (destructive interference) and consequently non-conducting nature in AQ. These features are in agreement with the switching mechanism of $\mathrm{AQ} / \mathrm{AQH}_{2}$ couple observed by Seidel et al. ${ }^{23}$

\section{Conclusions}

In the present study, an attempt has been made to understand the fundamental electrostatic nature of all possible reduction and protonation states of quinone, which may create attractive and repulsive forces with their receptors to fulfill their role in various processes. Moreover, it has been shown that quinones can act as molecular switch in their quinoidal and quinol states. That makes them potential candidates to control electronic conductivity through a molecular switch in molecular electronic devices.

In this paper, the three-dimensional MESP mapping of different reduction and protonation states of $p$-benzoquinone, is employed as a probe for exploring the electron distribution and its influence on the reactivity in the form of interactions with a model electrophile viz., $\mathrm{Li}^{+}$. A good correlation has been found between 
the MESP features and the corresponding pronounced $\mathrm{Li}^{+}$cation bonding strength. The salient feature of the present work is that under the impact of pronounced negative MESP values, reduced $p$-benzoquinone states, viz., $\mathrm{BQ}^{\bullet-}$ and $\mathrm{BQ}^{2-}$ interact strongly with an electrophile as modelled by $\mathrm{Li}^{+}$in comparison with neutral BQ. The study also suggests that the singly reduced state of quinone shows $\mathrm{H}$-bonding with protonated amino acids, viz., SER and HIS without having a possibility of proton transfer process. When protons are readily available, such as in the case of $\mathrm{NH}_{4}^{+}$, the proton transfer may occur from donor to singly reduced state of quinones. However, the dianion state of quinone can abstract the protons from protonated amino acids HIS and SER moieties. This gives an intuitive picture of the movement of reduced ubiquinone species towards the protonated amino acids in the photosynthetic RC, with major contribution from electrostatic interactions. Due to the analogous geometrical nature of the oxygen regions, we expect similar MESP features of other substituted quinone state of interest which are significant in various important biochemical and other chemical processes. It is hence hoped that the present work provides a first step towards understanding detailed mechanisms of quinone activity (such as its interactions with side chains and other electrophiles in RC) in these processes. Furthermore, the MESP topographical features of quinone states support the understanding of electron conductivity switching mechanism in $\mathrm{AQ} / \mathrm{AQH}_{2}$ redox system. ${ }^{22}$ The presence of conjugation between the rings of the $\mathrm{AQH}_{2}$ by means of central CCPs reveals their higher molecular electronic conductivity than AQ and consequently the switching mechanism. It illustrates the importance of roles of quinone redox states and their characteristic MESP features in modern molecular electronics.

\section{Supplementary Information (SI)}

Cartesian co-ordinates and energies of the optimized geometries of BQS (SI) and the complexes viz., $\mathrm{BQS}^{\cdots} \mathrm{Li}^{+}(\mathrm{SII})$, $\mathrm{BQS}^{\cdots} \mathrm{NH}_{4}^{+}$(SIII), BQS $\cdots$ SER (SIV) and BQS $\cdots$ HIS (SV) at B3LYP/6-311+G(d,p) (for closed shell states) and UB3LYP/ $6-311+\mathrm{G}(\mathrm{d}, \mathrm{p})$ (for open shell states) levels of theory are provided in the Supplementary Information, which is available at www.ias.ac.in/chemsci.

\section{Acknowledgements}

The APW and SSP gratefully acknowledge the Board of College and University Development (BCUD) and UPE Phase II budget, respectively, Savitribai Phule Pune University, Pune for financial support.

\section{References}

1. Heffner J E, Raber J C, Moe O A and Wigal C T 1998 Using cyclic voltammetry and molecular modelling to determine substituent effects in the one-electron reduction of benzoquinones J. Chem. Educ. 75365

2. Guin P S, Das S and Mandal P C 2011 Electrochemical reduction of quinones in different media: a review Int. $J$. Electrochem . 20111

3. Ernster L and Dallner G 1995 Biochemical physiological and medical aspects of ubiquinone function Biochim. Biophys. Acta 1271195

4. Marreiros B C, Calisto F, Castro P J, Duarte A M, Sena F V, Silva A F, Sousa F M, Teixeira M, Refojo P N and Pereira M M 2016 Exploring membrane respiratory chains Biochim. Biophys. Acta 18571039

5. Kato Y, Nagao R and Noguchi T 2016 Redox potential of the terminal quinone electron acceptor $\mathrm{Q}_{\mathrm{b}}$ in photosystem II reveals the mechanism of electron transfer regulation Proc. Natl. Acad. Sci. (U. S. A.) 113620

6. Okamura M Y, Paddock M L, Graige M S and Feher G 2000 Proton and electron transfer in bacterial reaction centres Biochim. Biophys. Acta 1458148

7. Feher G, Allen J C, Okamura M Y and Rees D C 1989 Structure and function of bacterial photosynthetic reaction centres Nature 339111

8. Nabedryk E and Breton J 2008 Coupling of electron transfer to proton uptake at the $\mathrm{QB}$ site of the bacterial reaction center: A perspective from FTIR difference spectroscopy Biochim. Biophys. Acta 17771229

9. Fyfe P K and Jones M R 2000 Re-emerging structures: continuing crystallography of the bacterial reaction centre Biochim. Biophys. Acta 1459413

10. Stowell M H B, McPhillips T M, Rees D C, Soltis S M, Abresch E and Feher G 1997 Light-induced structural changes in photosynthetic reaction center: implications for mechanism of electron-proton transfer Science $\mathbf{2 7 6}$ 812

11. Walden S E and Wheeler R A 2002 Protein conformational gate controlling binding site preference and migration for ubiquinone-b in the photosynthetic reaction center of Rhodobacter sphaeroides J. Phys. Chem. B 1063001

12. Lancaster C R D and Michel H 1997 The coupling of light-induced electron transfer and proton uptake as derived from crystal structures of reaction centres from Rhodopseudomonas viridis modified at the binding site of the secondary quinone, $\mathrm{Q}_{\mathrm{B}}$ Structure $\mathbf{5} 1339$

13. Zhu Z and Gunner M R 2005 Energetics of QuinoneDependent Electron and Proton Transfers in Rhodobacter sphaeroides Photosynthetic Reaction Centers Biochemistry $\mathbf{4 4} 82$

14. Breton J, Boullais C, Mioskowski C, Sebban P, Baciou L and Nabedryk E 2002 Vibrational spectroscopy favors a unique $\mathrm{Q}_{\mathrm{B}}$ binding site at the proximal position in wildtype reaction centers and in the Pro-L209 $\rightarrow$ Tyr Mutant from Rhodobacter sphaeroides Biochemistry 4112921

15. Takahashi E and Wraight C A 1996 Potentiation of proton transfer function by electrostatic interactions in photosynthetic reaction centers from Rhodobacter sphaeroides : first results from site-directed mutation of the H subunit Proc. Natl. Acad. Sci. U. S. A. 932640 
16. Manojkumar T K, Choi H S, Tarakeshwar P and Kim K S $2003 \mathrm{Ab}$ initio studies of neutral and anionic p-benzoquinone-water clusters J. Chem. Phys. 118 8681

17. Nepal B and Scheiner S 2016 Enhancing the reduction potential of quinones via complex formation J. Org. Chem. 814316

18. Darwish N, Díez-Pérez I, Da Silva P, Tao N, Gooding J J and Paddon-Row M N 2012 Observation of electrochemically controlled quantum interference in a single anthraquinone-based norbornylogous bridge molecule Angew. Chem. Int. Edit. 513203

19. Baghernejad M, Zhao X, Ørnsø K B, Füeg M, MorenoGarcía P, Rudnev A V, Kaliginedi V, Vesztergom S, Huang C, Hong W, Broekmann P, Wandlowski T, Thygesen K S and Bryce M R 2014 Electrochemical control of single-molecule conductance by fermi level tuning and conjugation switching J. Am. Chem. Soc. 136 17922

20. van Dijk E H, Myles D J T, van der Veen M H and Hummelen J C 2006 Synthesis and properties of an anthraquinone-based redox switch for molecular electronics Org. Lett. 82333

21. Xiang D, Wang X, Jia C, Lee T and Guo X 2016 Molecular-scale electronics: from concept to function Chem. Rev. 1164318

22. Markussen T, Schiötz J and Thygesen K S 2010 Electrochemical control of quantum interference in anthraquinone-based molecular switches J. Chem. Phys. 132224104

23. Seidel N, Hahn T, Liebing S, Seichter W, Jens K and Weber E 2013 Synthesis and properties of new 9,10-anthraquinone derived compounds for molecular electronics New J. Chem. 37601

24. Greene L E, Godin R and Cosa G 2016 Fluorogenic ubiquinone analogue for monitoring chemical and biological redox processes J. Am. Chem. Soc. 13811327

25. Nonella M 1997 Structures and vibrational spectra of $p$-benzoquinone in different oxidation and protonation states: a density functional study J. Phys. Chem. B 101 1235

26. Boesch S E and Wheeler R A $1997 \pi$-Donor substituent effects on calculated structures spin properties and vibrations of radical anions of $p$-chloranil $p$-fluoranil and p-benzoquinone J. Phys. Chem. A 1018351

27. Brandt U and Trumpower B L 1994 The protonmotive Q cycle in mitochondria and bacteria Crit. Rev. Biochem. 29165

28. Trumpower B L and Gennis R B 1994 Energy transduction by cytochrome complexes in mitochondrial and bacterial respiration: the enzymology of coupling electron transfer reactions to transmembrane proton translocation Annu. Rev. Biochem. 63675

29. O'Malley P J 1997 A density functional study of the effect of reduction on the geometry and electron affinity of hydrogen bonded 1,4-benzoquinone implications for quinone reduction and protonation in photosynthetic reaction centres Chem. Phys. Lett. 274251

30. Nonella M, Mathias G and Tavan P 2003 Infrared spectrum of $p$-benzoquinone in water obtained from a QM/MM hybrid molecular dynamics simulation J. Phys. Chem. A 1078638
31. Pou-Amérigo R, Merchán M and OrtíE 1999 Theoretical study of the electronic spectrum of $p$-benzoquinone $J$. Chem. Phys. 1109536

32. Zhao X, Imahori H, Zhan C-G, Sakata Y, Iwata S and Kitagawa T 1997 Resonance Raman and FTIR spectra of isotope-labeled reduced 1,4-benzoquinone and its protonated forms in solutions J. Phys. Chem. A 101622

33. Politzer P and Truhlar D G 1981 In Chemical applications of atomic and molecular electrostatic potentials (New York: Plenum)

34. Politzer P, Landry S J and Wärnhelm T J 1982 Proposed procedure for using electrostatic potentials to predict and interpret nucleophilic processes J. Phys. Chem. 86 4767

35. Sjöberg P and Politzer P 1990 Use of the electrostatic potential at the molecular surface to interpret and predict nucleophilic processes J. Phys. Chem. 943959

36. Tomasi J, Bonaccrosi R and Cammi R 1990 In: Theoretical methods of chemical bonding, Part 3 Maksic Z B (Ed.) (New York: Springer) and references therein

37. Gadre S R, Pundlik S S and Shrivastava I H 1994 A "Critical" appraisal of electrostatic charge models for molecules Proc. Ind. Acad. Sci. (J. Chem. Sci.) 106303

38. (a) Orozco M and Luque J 1996 in Molecular electrostatic potentials concepts and applications Vol. 3. J S Murray and K D Sen (Eds.) (Amsterdam: Elsevier) and references therein; (b) Gadre S R, Bhadane P K, Pundlik S S and Pingale S S 1996 In Molecular electrostatic potentials concepts and applications Vol. 3. J S Murray and K D Sen (Eds.) (Amsterdam: Elsevier) and references therein; (c) Roy D K, Balanarayan P and Gadre S R 2009 Signatures of molecular recognition from the topography of electrostatic potential J. Chem. Sci. 121 815

39. Gejji S P, Suresh C H, Bartolotti L J and Gadre S R 1997 Electrostatic potential as a harbinger of cation coordination: $\mathrm{CF}_{3} \mathrm{SO}^{3-}$ ion as a model example J. Phys. Chem. 1015678

40. Pingale S S, Gadre S R and Bartolotti L J 1998 Electrostatic insights into the molecular hydration process: a case study of crown ethers J. Phys. Chem. A 1029987

41. Gadre S R and Bhadane P K 1997 Patterns in hydrogen bonding via electrostatic potential topography J. Chem. Phys. 1075625

42. Gadre S R and Pundlik S S 1997 Complementary electrostatics for the study of DNA base-pair interactions $J$. Phys. Chem. B 1013298

43. Lancaster C R D 2003 The role of electrostatics in protonconducting membrane protein complexes FEBS Lett . 54552

44. Sharma B, Neela Y I and Sastry G N 2016 Structures and energetics of complexation of metal ions with ammonia water and benzene: a computational study J. Comp. Chem. 37992

45. Bhattacharjee A K, Pundlik S S and Gadre S R 1997 Conformational and electrostatic properties of naphthazarin, juglone and naphthoquinone: an ab initio theoretical study Cancer. Invest. 15531

46. Abroshan H, Dhumal N R, Shimb Y and Kim H J 2016 Theoretical study of interactions of a $\mathrm{Li}^{+}\left(\mathrm{CF}_{3} \mathrm{SO}_{2}\right)_{2} \mathrm{~N}^{-}$ ion pair with $\mathrm{CR}_{3}\left(\mathrm{OCR}_{2} \mathrm{CR}_{2}\right) \mathrm{nOCR}_{3}(\mathrm{R}=\mathrm{H}$ or $\mathrm{F})$ Phys. Chem. Chem. Phys. 186754 
47. Gadre S R and Bhadane P K 1998 Complexes of ammonia with propane and cyclopropane: electrostatic guidelines for $a b$ initio treatment Theor. Chem. Acc. 100 300

48. Pingale S S 2011 Molecular electrostatic potential for exploring $\pi$-conjugation: a density-functional investigation Phys. Chem. Chem. Phys. 1315158

49. Gaussian 09 Revision A 02 Frisch M J, Trucks G W, Schlegel H B, Scuseria G E, Robb M A, Cheeseman J R, Scalmani G, Barone V, Petersson G A, Nakatsuji H, Li X, Caricato M, Marenich AV, Bloino J, Janesko B G, Gomperts R, Mennucci B, Hratchian H P, Ortiz J V, Izmaylov A F, Sonnenberg J L, Williams-Young D, Ding F, Lipparini F, Egidi F, Goings J, Peng B, Petrone A, Henderson T, Ranasinghe D, Zakrzewski V G, Gao J, Rega N, Zheng G, Liang W, Hada M, Ehara M, Toyota K, Fukuda R, Hasegawa J, Ishida M, Nakajima T, Honda Y, Kitao O, Nakai H, Vreven T, Throssell K, Montgomery J A Jr, Peralta J E, Ogliaro F, Bearpark M J, Heyd J J, Brothers E N, Kudin K N, Staroverov V N, Keith T A, Kobayashi R, Normand J, Raghavachari K, Rendell A P, Burant J C, Iyengar S S, Tomasi J, Cossi M, Millam J M, Klene M, Adamo C, Cammi R, Ochterski J W, Martin R L, Morokuma K, Farkas O, Foresman J B and Fox D J 2009 Gaussian Inc, Wallingford CT.

50. The topographical analysis is brought out in term of characterizing the critical points (CPs) where the first order partial derivatives of this field vanish. The CPs are represented by a notation (rank, signature) where rank is the number of nonzero eigenvalues of the Hessian matrix and signature is the algebraic sum of the signs of these eigenvalues. The non-degenerate CPs are further char- acterized viz., minimum $(3,+3)$, maximum $(3,-3)$ or saddles of types $(3,+1)$ and $(3,-1)$.

51. Shirsat R N, Bapat S V and Gadre S R 1992 Molecular electrostatics: a comprehensive topographical approach Chem. Phys. Lett. 200373

52. Kulkarni S A 1996 Electron correlation effects on the topography of molecular electrostatic potentials Chem. Phys. Lett. 254268

53. Gadre S R, Kulkarni S A, Suresh C H and Strivastava I H 1995 Basis set dependence of the molecular electrostatic potential topography a case study of substituted benzenes Chem. Phys. Lett. 239273

54. Limaye A C and Gadre S R 2001 UNIVIS-2000: An indigenously developed comprehensive visualization package Curr. Sci. (India) 801296

55. Boys S F and Bernardi F 1970 The calculation of small molecular interactions by the differences of separate total energies. Some procedures with reduced errors $\mathrm{Mol}$. Phys. 19553

56. Zhao Y and Truhlar D G 2008 The M06 suite of density functionals for main group thermochemistry, thermochemical kinetics, noncovalent interactions, excited states, and transition elements: two new functionals and systematic testing of four M06-class functionals and 12 other functionals Theor. Chem. Acc. 120, 215

57. Pathak R K and Gadre S R 1990 Maximal and minimal characteristics of molecular electrostatic potentials J. Chem. Phys. 931770

58. Bijina P V, Suresh C H and Gadre S R 2018 Electrostatics for probing lone pairs and their interactions J. Comput. Chem. 39488 